\title{
The effects of different exercise conditions on metacarpal bone strains in Thoroughbred racehorses
}

Helen M. S. Davies

Equine Clinical Research Unit, Department of Veterinary Science, University of Melbourne, Australia

\begin{abstract}
Summary
Excessive strains are thought to cause dorsal metacarpal disease (shin-soreness) in young Thoroughbred racehorses. Strains were measured on the dorsal cortex of the third metacarpal bones in 6 yearling (16 to 19 months old) and 6 adult (4 to 8 years old) Thoroughbred horses during exercise on a treadmill and on different track surfaces (sand, grass, woodchip, bitumen and dirt).

Strains were always higher on the outside limb than the inside limb during turns. Strains were higher in the non-lead limb than the lead limb in canter and gallop. Strains increased with fatigue. Changing the track surface, inclining the treadmill to $5.2^{\circ}$ and changing the angle of the ground reaction force by changing hoof balance did not increase strains. These findings suggest that track shape will directly affect the incidence of shin soreness, while track surface and camber will not have a direct effect.
\end{abstract}

Keywords: $\quad$ horses, metacarpal bone, strain, exercise.

\section{Effekte verschiedener Trainingsbedingungen auf die Belastung der Metacarpalknochen bei Galopprennpferden}

Es wird angenommen, daß hohe Trainings- und Rennbelastungen bei jungen Galopprennpferden eine Erkrankung des dorsalen Metacarpus (Schienbeinerkrankung) hervorrufen können. Die während des Trainings auf dem Laufband und auf verschiedenen Böden (Sand, Gras, Holzspäne, Asphalt und Dirttrack) an der dorsalen Kortikalis des Metacarpus (Mclli) auftretenden Belastungen wurden bei sechs Vollblutjährlingen (16 bis 19 Monate alt) und bei sechs erwachsenen Vollblutpferden (im Alter von 4 bis 8 Jahren) gemessen.

Im Bogen der Trainings- oder Rennbahn war die Belastung auf dem äußeren Bein immer höher als auf dem inneren. Im Canter und Galopp war die Belastung auf dem nicht-führenden Bein höher als auf dem führenden. Die Belastung nahm bei Ermüdung zu. Die Belastung wurde weder durch eine andere Bodenart noch durch eine Laufbandsteigung von 5,2 erhöht. Auch eine Veränderung der Hufbalance und des Auffußungswinkels bewirkten keine höhere Belastung des Mclll.

Dies weist darauf hin, daß die Abmessung und Linienführung der Bahn das Auftreten der Schienbeinerkrankung direkt beeinflussen, wohingegen die Art des Bodens keinen direkten Einfluß hat.

Schlüsselwörter: Pferde, Metacarpalknochen, Belastung, Training

\section{Introduction}

The degree of bone deformation (ie. strain) during locomotion of animals and humans can be assessed using strain gauges (Lanyon 1976). Excessive strain on the dorsal cortex of the third metacarpal bone (MC3) is thought to result in dorsal metacarpal disease (shin soreness) which is a painful condition of young racehorses (Nunamaker et al. 1990).

In previous experiments we measured strains on the dorsal surface of MC3 of adult and yearling Thoroughbreds using stacked rosette strain gauges under strictly controlled conditions of exercise (Davies et al. 1993, Davies \& McCarthy 1994). These studies showed that there was compression of the dorsal cortex of MC3 at speeds ranging from 4 to $16.5 \mathrm{~ms}^{-1}$ and that the magnitude of compression and the rate of compression were proportional to the speed of exercise. Strains shown by the yearlings were about $25 \%$ higher than those recorded from the MC3 of adult Thoroughbreds under similar exercise conditions.

It was concluded that the higher strains may predispose the young Thoroughbred racehorses to shin soreness and that faster speeds of exercise were required to cause these high strains. It is possible that other factors as well as exercise speed are involved in the pathogenesis of shin soreness. In this study the strains on the dorsal surface of MC3 were measured with the horses subjected to a range of different exercise conditions.

\section{Materials and methods}

\section{Strain Gauge Preparation}

Rectangular stacked rosette strain gauges (WA-09-120WR-350, MicroMeasurements, Rayleigh, North Carolina) were used. They were packaged and implanted under general anaesthesia onto the dorsal cortex of the midshaft of both third metacarpal bones according to the methods described previously (Davies et al. 1993).

\section{Animals}

Six yearling Thoroughbred horses ( 4 colts and 2 fillies), aged from 16 to 19 months and 6 experienced adult racehorses (1 mare and 5 geldings) ranging in age from 4 to 8 years were used. All these horses were accustomed to the treadmill in 6 short sessions spread over 2 weeks. The yearlings were otherwise untrained.

The horses were bandaged to protect the implantation site and reduce movement of the wires at the skin exit hole. None of the horses were clinically lame during the measurement period. The only time the horses showed any soreness was when the bandage moved and this was always rectified by careful re-bandaging. All the horses were given oral anti-inflammatory medication with phenylbutazone (Equipalazone, Arnolds of Reading), at a dose rate of $1 \mathrm{~g} \mathrm{day}^{-1}$ throughout the period of investigation. The first measurements were taken the day after surgery and repea- 
ted twice daily for the next week. At the end of the study all horses were killed and the orientation of the gauges to the longitudinal axis of MC3 measured with a protractor at post mortem.

\section{Strain Recording on the Treadmill}

The gauges were connected to signal conditioning amplifiers (2120A Micromeasurements, Raleigh, North Carolina) and were zeroed at the beginning of each exercise session with the forelimb lifted. Strain gauge data were collected simultaneously from all 3 gauges of a rosette directly into a computer (MacSE-30) via an AVD converter (MacLab, Analogue Digital Instruments, Sydney, NSW) at a sampling rate of $40 \mathrm{~Hz}$ per channel. The peak principal strain on the bone and the direction of that principal strain were determined by combining the data from the 3 gauges using the principles of Mohr circle analysis (Dally \& Riley 1978). In each horse the mean minimum principal strain for 6 strides at each speed were calculated for both forelimbs.

\section{Telemetric System for Strain Recording}

The telemetric system consisted of two F-1101 $49 \mathrm{MHz}$ strain gauge transmitters (Binsfield Engineering Inc. Maple City, Ml., USA) each powered by $29 \mathrm{~V}$ lithium batteries and set to transmit on different frequencies ( 49.83 and $49.89 \mathrm{MHz}$ ). These transmitters were each wired up with Wheatstone bridge completion circuits (MRI-350-127 Measurements Group Inc., Raleigh, North Carolina, USA) and an extra 500 resistor to increase the full scale strain output of the transmitter.

The signals from the transmitters were received by two receiver/demodulators (49MHz Model F-2002, Binsfield Engineering Inc., Maple City, MI., USA) and passed via the analog/digital converter (MacLab, Analogue Digital Instruments, Sydney, NSW) directly to the computer (MacSE-30). Aerials were extended from the receiver out either side of the measurement station for 20 to $50 \mathrm{~m}$ and data was collected while the horse was in range of these aerials.

The transmitters were fitted into specially made pockets and fixed with Velcro tapes to a surcingle which was attached firmly around the horse's girth or looped around in front of the saddle and taped to the saddle if the horse was to be ridden. Extra aerial wires were fixed to each transmitter aerial and run from the transmitters up the neck on either side of the mane to the headcollar to which they were attached with tape. Each transmitter was wired up to the central gauge of a rosette via a lead wire that was taken up each forelimb from the gauge site.

\section{Exercise and Recording}

The horses were exercised on a treadmill at 2, 4, 6, 8, 10, 12 and $14 \mathrm{~ms}^{-1}$ for at least 10 strides at each speed. Some horses did more than one gait at a specific speed so strain differences due to the gait could be estimated.

Runs at the standard speeds were repeated with the following changes to the basic experimental conditions:

1. The yearlings were given a standard run up to whatever speed they could maintain easily with the treadmill inclined to $5.2^{\circ}$.

2. Both yearlings and adults were given a standard run on the flat treadmill, followed by runs with 2 different weights on their backs. This weight consisted of a racing exercise saddle and surcingle with saddle cloths, between which rested a bag into which flat plates of lead were inserted and bent in such a way that they did not interfere with the horse's limb movements. The weights the yearlings carried were 10 and $20 \mathrm{~kg}$. The adults carried 20 and $60 \mathrm{~kg}$.
3. The yearlings were shod with front shoes only and given a standard run to a speed that they could achieve without apparent stress. The adults had shoes put on all 4 hooves and were given a standard run. Then the front shoes of the adults were removed and replaced with heel wedges or with a wedge in the lateral sides of both front hooves or with shoes with an extended toe.

4. The central gauges of the 2 rosettes were attached to the telemetric equipment and the horse was lunged or ridden by an $80 \mathrm{~kg}$ rider on different surfaces at the walk and trot in both directions; and, where conditions permitted, the canter and gallop too. The different surfaces included sand, grass, dirt, woodchip and bitumen.

5. Horses were worked in a straight line and in a circle (10 to $15 \mathrm{~m}$ diameter) on the same surface at similar speeds so that strains shown by the inside limb and outside limb and limbs moving straight ahead could be compared. Speed on a circle was estimated by measuring the time taken to complete a circle with a stopwatch, and dividing this into the circumference of the circle calculated using the length of the lunge line as the radius (circumference $=2 \pi r$ ). This strain data was calibrated with data obtained with the telemetric system during a standard run at $2,4,6,8,10,12$, and $14 \mathrm{~ms}^{-1}$ on the treadmill at zero incline.

\section{Results}

When a horse was exercised around a turn, the strains collected from the dorsal surface of MC3 on the outside limb were consistently higher than those collected from the inside limb at a similar gait and speed (Tab. 1 and 2). With smaller circles the strains collected were higher. With faster speeds on the same size circle

Tab. 1: Mean peak strains ( $\mu$ strains $\pm S D$ ) recorded telemetrically from the central gauges of rosette strain gauges on the mid shaft dorsal metacarpal cortex of 6 yearling Thoroughbred horses. Strains were recorded from the inside and outside limbs during left and right turns on the lunge at the trot and canter. The circle diameter was 10 to 15 metres. Trot was between 4 and $7 \mathrm{~ms}^{-1}$. Canter was between 7 and $10 \mathrm{~ms}^{-1}$.

\begin{tabular}{|l|c|c|}
\hline $\begin{array}{l}\text { Limb position in relation to } \\
\text { the direction of movement }\end{array}$ & Gait & $\begin{array}{c}\text { MC3 strains } \\
(\mu \text { strains } \pm \text { SD })\end{array}$ \\
\hline inside limb in a turn & trot & $3190 \pm 1250$ \\
\hline outside limb in a turn & trot & $4291 \pm 861$ \\
\hline $\begin{array}{l}\% \text { increase in strain } \\
\text { in the outside limb } \\
\text { compared with } \\
\text { the inside limb in a turn }\end{array}$ & trot & $145 \% \pm 39 \%$ \\
\hline $\begin{array}{l}\text { inside limb on a turn } \\
\text { with the inside limb leading }\end{array}$ & canter & $4095 \pm 1242$ \\
\hline $\begin{array}{l}\text { outside limb on a turn } \\
\text { with the inside limb leading }\end{array}$ & canter & $4671 \pm 1064$ \\
\hline $\begin{array}{l}\% \text { increase in strain } \\
\text { in the outside limb } \\
\text { compared with } \\
\text { the inside limb in a turn }\end{array}$ & canter & $118 \% \pm 13 \%$ \\
\hline
\end{tabular}


the difference between inside and outside limbs increased. The strains on the outside limb were 4 times the strains on the inside limb at approximately $12 \mathrm{~ms}^{-1}$ on a $15 \mathrm{~m}$ circle. The longitudinal compressive strains on the dorsal surface of MC3 in both forelimbs were greater during turning than during exercise in a straight line at a similar speed (Tab. 2).

The strains on MC3 increased by up to $20 \%$ when the horses tired as shown by an inability to reach a previous peak exercise speed in a subsequent run within the same exercise period. With some horses there was a transient non-significant decrease in strains measured when the horse was first worked with a new treatment (lead weights, shoes, heel wedges, elongated toes, lateral wedges). This was most consistent in the yearlings with the first run with weight on their backs ( 4 of 6 yearlings showed a transient decrease in strains). These horses appeared to increase the relative loading of their hind limbs.

Strains collected during different gaits at the same speed in the same run are presented in Tab. 3. Strain differences between gaits were very consistent within a particular limb of a particular horse between runs. There was a reduction in strain in the leading limb when horses changed from trot to canter. Strains collected

Tab. 2: Mean peak strains ( $\mu$ strains $\pm \mathrm{SD}$ ) recorded telemetrically from the central gauges of rosette strain gauges on the mid dorsal metacarpal cortex of 6 adult Thoroughbred horses. Strains were recorded simultaneously from the inside and outside limbs during left and right turns on the lunge (10 to 15 metre diameter circle) at the trot and canter and from the leading limb and non-lead limb at the canter in a straight line when ridden by an $80 \mathrm{~kg}$ jockey. Trot speeds were between 3 and $9 \mathrm{~ms}^{-1}$. Canter speeds were between 5 and $14 \mathrm{~ms}^{-1}$.

\begin{tabular}{|l|c|c|}
\hline $\begin{array}{l}\text { Limb position in relation to } \\
\text { the direction of movement }\end{array}$ & Gait & $\begin{array}{c}\text { Mean peak } \\
\text { MC3 strains } \\
(\mu \text { strains } \pm \text { SD })\end{array}$ \\
\hline inside limb in a turn & trot & $1141 \pm 423$ \\
\hline outside limb in a turn & trot & $1889 \pm 497$ \\
\hline $\begin{array}{l}\% \text { increase in strain in } \\
\text { the outside limb } \\
\text { compared with } \\
\text { the inside limb in a turn }\end{array}$ & canter & $182 \% \pm 87 \%$ \\
\hline $\begin{array}{l}\text { inside limb on a turn } \\
\text { with the inside limb leading }\end{array}$ & canter & $3402 \pm 1397$ \\
\hline $\begin{array}{l}\text { outside limb on a turn } \\
\text { with the inside limb leading }\end{array}$ & canter & $252 \% \pm 108 \%$ \\
\hline $\begin{array}{l}\% \text { increase in strain in } \\
\text { the outside limb } \\
\text { compared with } \\
\text { the inside limb in a turn }\end{array}$ & canter & $827 \pm 294$ \\
\hline $\begin{array}{l}\text { moving straight ahead } \\
\text { leading limb }\end{array}$ & canter \\
\hline $\begin{array}{l}\text { moving straight ahead } \\
\text { non-lead limb }\end{array}$ & $969 \pm 380$ \\
\hline $\begin{array}{l}\text { compared with leading limb } \\
\text { conb }\end{array}$ & $117 \% \pm 9 \%$ \\
\hline
\end{tabular}

from the non-lead limb were greater than strains collected simultaneously from the leading limb (Tab. 2 and 3).

There were no consistent differences in strains recorded from the dorsal cortex of MC3 during exercise on the different surfaces.

No increases in strains on MC3 were recorded with the addition of different weights to a saddle on the back of the horse. No increases in strain were recorded with inclining the treadmill to $5^{\circ}$, shoeing the front limbs in the yearlings, or symmetrically altering both front hoof angles with heel wedges, lateral wedges, or elongated toes in the adult horses.

\section{Discussion}

This study showed that longitudinal compressive strains increased on the dorsal MC3 cortex when horses were exercised around a turn. The highest strains occurred in the outside limb. These high strains may occur when the forces directed through the forelimbs to withstand centrifugal forces and change the direction of the body are added to the dynamic forces due to limb movement.

An increase in fatigue as shown by an inability to attain a previous maximum exercise speed in a subsequent run within the same exercise period was associated with an increase in bone strain. Bone strain has been shown to increase by 26 to $35 \%$ in the canine tibia when muscles became fatigued (Yoshikawa et al. 1993). The MC3 in horses has minimal muscle attachments compared to the canine tibia so it is unlikely to experience the same level of effect on strains from changes in muscle activity. There was no distinction made in this experiment between possible effects of muscle fatigue within the limb (eg extensor carpi radialis), and the possible effects of muscle fatigue in changing the relative loading of the fore and hind limbs. Further, the horses were not pushed to exhaust themselves, but were allowed to stop when they ceased being able to attain a previous top speed. The effects of fatigue in this experiment are therefore minor compared with what might be expected to occur when horses have an added stimulation to exercise faster (eg other horses and whips). There were no consistent differences between different surfaces in the strains recorded. This suggests that the effect of surface on the occurrence of shin soreness (Moyer et al. 1991) is secondary to the effects on other locomotory parameters. This finding agrees with Gross et al. (1990) who reported that when horses were exercised on a soft sand track and a treadmill there were no differences in the size or distribution of strains around the mid-shaft of MC3. However there is an unconfirmed report of a $10 \%$ reduction in peak strains on the dorsal MC3 of horses exercising at the same speed on the same day on wood fibre compared with dirt track surfaces (Nunamaker cited by Moyer et al. 1991). As these measurements were taken "on the same day" this difference between tracks may have been due to fatigue or other effects on the relative loading of the fore and hind limbs. It seems likely that a wood fibre track might supply more elastic recoil and therefore increase the efficiency of locomotion and the time to fatigue compared with a hard dirt track.

There may be a reduction in strain on the dorsal MC3 when horses canter as apposed to trotting (Tab. 3). This finding suggests that the differences in bone shape recorded in racing Standardbreds and Thoroughbreds (McCarthy 1989, Nunamaker et al. 1989) were not a direct function of differences in the racing gait. The shape differences between the breeds may be more due to the faster speeds of the Thoroughbred (inducing bone modelling in response to the high strains on the dorsal surface) and the in- 
Tab. 3: Percentage change in mean peak strains on the dorsal third metacarpus of a specific limb with change in gait between trot and canter. Strains were recorded from rosette strain gauges on the mid dorsal metacarpal cortex of 5 yearling Thoroughbred horses during exercise on a flat treadmill at a constant speed. Strains were recorded during trot and canter in the same run at $6 \mathrm{~ms}^{-1}$ except for horse 2 which was measured at $10 \mathrm{~ms}^{-1}$. $L$ refers to the left limb and $R$ to the right. NR not recorded.

\begin{tabular}{|l|c|c|c|c|c|c|}
\hline \multirow{2}{*}{ Gait change } & \multicolumn{5}{|c|}{$\begin{array}{c}\text { Horse number } \\
\text { and limb measured }\end{array}$} & \multirow{2}{*}{$\begin{array}{c}\text { Mean } \\
\pm \text { SD }\end{array}$} \\
\cline { 2 - 6 } & $1 \mathrm{~L}$ & $\begin{array}{c}2 \mathrm{~L} \\
2 \mathrm{R}\end{array}$ & $3 \mathrm{~L}$ & $\begin{array}{c}4 \mathrm{~L} \\
4 \mathrm{R}\end{array}$ & $5 \mathrm{R}$ & \\
\cline { 2 - 6 } & \multicolumn{5}{|c|}{$\begin{array}{c}\text { \% change in strain } \\
\text { with change in gait }\end{array}$} & \\
\hline $\begin{array}{l}\text { trot changing to } \\
\text { canter lead }\end{array}$ & 76 & $\begin{array}{c}\text { NR } \\
88\end{array}$ & 97 & $\begin{array}{c}73 \\
\text { NR }\end{array}$ & NR & $84 \pm 11$ \\
\hline $\begin{array}{l}\text { trot changing to } \\
\text { non-lead canter }\end{array}$ & 91 & $\begin{array}{c}79 \\
\text { NR }\end{array}$ & 104 & $\begin{array}{c}\text { NR } \\
93\end{array}$ & 103 & $94 \pm 10$ \\
\hline $\begin{array}{l}\text { canter lead } \\
\text { changing to } \\
\text { non-lead canter }\end{array}$ & 120 & $\begin{array}{c}\text { NR } \\
\text { NR }\end{array}$ & 107 & NR & NR & $114 \pm 9$ \\
\hline
\end{tabular}

creased amounts of lower speed exercise in the Standardbred horses (inducing more bone growth in other parts of the MC3).

All the horses in this study took the lead appropriate to the direction of turn (left to the left and vice versa), so the effect of canter lead was added to the effect of turning on the outside limb. The peak strains on the dorsal cortex of MC3 were greater in the nonlead forelimb at the canter and gallop (Tab. 2 and 3). The nonlead limb lands before the leading limb in each gait cycle so may be required to resist more of the dynamic forces involved in movement than the leading limb.

Shin soreness has been observed to show an increased incidence in the left limb when horses are exercised anti-clockwise (Stover 1987; Moyer et al. 1991). This is contrary to the effect of the turn on bone strains in this area. Inexperienced young racehorses exercising at the gallop anti-clockwise often take the right lead gallop around the turns (clinical observation). Considering the dynamics of limb movement during the canter it seems likely that the effect of canter lead on the strains on the dorsal surface of MC3 would be greater than the effect of turning. Whichever limb was the first to land in any stride would be exposed to the highest strain. Unfortunately no data was collected to confirm or refute this hypothesis.

The initial effects of increasing the weight carried by the horses was either no change in strains or a transient and variable decrease. A decrease in strains could occur if the horse increased the relative loading of the hind limbs. A similar increased loading of the hind limbs might explain the reduction in strains seen in some of the yearlings when they were shod in front and in some of the adults when their forefoot balance was disturbed with the use of side wedges, heel wedges, or elongated toes. The variable decrease in strains seen with the inclined treadmill may be explained in a similar way.

The maximum strains recorded from the metacarpus of Thoroughbred racehorses in this study were similar to the maximum strains
Tab. 4: Mean peak principal strains ( $\mu$ strains $\pm S D$ ) measured by rosette strain gages on the dorsal cortex of the 3rd metacarpus of 6 adult and 6 yearling Thoroughbred racehorses during exercise on a treadmill at zero incline.

\begin{tabular}{|l|c|c|c|c|c|c|}
\hline \multirow{2}{*}{} & \multicolumn{6}{|c|}{ Treadmill speed $\left(\mathrm{ms}^{-1}\right)$ and gait } \\
\cline { 2 - 7 } & $\begin{array}{c}2 \\
\text { Walk }\end{array}$ & $\begin{array}{c}4 \\
\text { Trot }\end{array}$ & $\begin{array}{c}6 \\
\text { Trot }\end{array}$ & $\begin{array}{c}8 \\
\text { Canter }\end{array}$ & $\begin{array}{c}10 \\
\text { Canter }\end{array}$ & $\begin{array}{c}12 \\
\text { Gallop }\end{array}$ \\
\hline $\begin{array}{l}\text { Yearling } \\
\text { MC3 }\end{array}$ & -997 & -1709 & -2289 & -3002 & -3663 & -4102 \\
strains & \pm 371 & \pm 459 & \pm 473 & \pm 553 & \pm 613 & \pm 722 \\
( $\mu$ strains) & & & & & & \\
\hline $\begin{array}{l}\text { Adult } \\
\text { MC3 }\end{array}$ & -571 & -1227 & -1653 & -2163 & -2503 & -2530 \\
strains & \pm 426 & \pm 441 & \pm 575 & \pm 639 & \pm 709 & \pm 971 \\
\hline ( $\begin{array}{l} \\
\text { Mstrains) }\end{array}$ & & & & & & \\
\hline
\end{tabular}

(-5670 $\mu$ strain) reported in young horses at racing speed by Nunamaker et al. (1990). The strain data obtained in this study demonstrated that in yearling Thoroughbreds the dorsal cortex of the metacarpal bones was subjected to higher strains than adults throughout the range of speeds used during normal training, and especially during turning. In the yearlings, the strains recorded at $10 \mathrm{~ms}^{-1}$ and above in a straight line exceed the peak $(2,000$ to $3,500 \mu$ strains) measured in bones over a wide range of species and ages of animal (Biewener et al. 1986). This finding indicated that the dorsal cortex of the yearling metacarpus has probably not modelled sufficiently to withstand the normal locomotory forces at this age.

In conclusion, the dynamic effects of exercise speed and steepness of turn cause high strains on the dorsal surface of MC3, and not the static effects of weight, track surface, or the angle of the ground reaction force. Therefore track shape will directly affect the incidence of shin soreness, while track surface and camber will not have a direct effect. Horses may temporarily reduce the dorsal MC3 strains by increasing the relative loading of the hind limbs. This may explain the transient and variable strain decrease recorded in some treatments. Increased weight carried by the horse and less elastic or heavier track surfaces may indirectly cause increased strain by tiring the horse. This may explain differences between track surfaces in the occurrence of shinsoreness.

\section{References}

Biewener, A. A., and Taylor, C. R. (1986): Bone strain: a determinant of gait and speed? J. Exp. Biol. 123,383-400.

Dally, J. and Riley, W. (1978): Experimental stress analysis. McGrawHill, New York.

Davies, H. M. S., McCarthy, R. N. and Jeffcott, L.B. (1993): Surface strain on the dorsal metacarpus of Thoroughbreds at different speeds and gaits. Acta Anatomica. 146,148-153.

Davies H. and McCarthy R., (1994): Surface strain on the dorsomedial metacarpus of yearling thoroughbreds at different speeds and gaits on a treadmill. Equine Vet J. Suppl 17, 25-28. 
Gross, T. S., McLeod, K. J. and Rubin, C.T. (1990): The skeletal consequences of extreme physical activity:The comparative strain milieu generated by treadmill and field conditions. 36th Ann. Meet. Orthop. Res. Soc. p108.

Lanyon, L. (1976): The measurement of bone strain in vivo. Acta Orthop. Belg. 42, 98-108

McCarthy, R. N. (1989): The effect of exercise on bone development in the horse. PhD Thesis, University of Melbourne.

Moyer W., Spencer P. and Kallish M., (1991): Relative incidence of dorsal metacarpal disease in young thoroughbred racehorses training on two different surfaces. Equine Vet J. 23, 166-168.

Nunamaker, D. M., Butterweck, D. M. and Provost, M. T. (1989): Some geometric properties of the 3rd metacarpal bone: A comparison between the Thoroughbred and Standardbred racehorse. J. Biomech. 22, 1229-134.

Nunamaker, D. M., Butterweck, D. M. and Provost, M. T. (1990): Fatigue fractures in thoroughbred racehorses: Relationships with age, peak bone strain, and training. J. Orthop. Res. 8, 604-611.

Stover, S.M. (1987): Dorsal metacarpal disease in thoroughbred horses: Development of the third metacarpal bone. PhD Thesis. University of California, Davis.
Yoshikawa, T., Mori, S., Santiesteban, A., Sun, T., Hafstad, E., Chen, $J$. and Burr, D. (1993): The effects of muscle fatigue on bone strain.

J. exp. Biol. 188, 217-233.

\section{Acknowledgments}

Thanks are due to Mr. M. Wilson, Mr. P. Coates, Mr. A. Alder and Mrs. M. Jones for their technical assistance. This project was supported by grants from the Australian Equine Research Foundation, the Melbourne University Equine Research Fund and the Victorian Department of Sport and Recreation.

Helen M. S. Davies

Equine Clinical Research Unit

Department of Veterinary Science

University of Melbourne

Princes Highway, Werribee

Victoria 3030, Australia

Fax (00613) 97410401

\title{
Bundesverband Praktischer Tierärzte \\ Kongreß 96 - Pferdekrankheiten
}

\author{
5.-6. September 1996
}

Nürnberg

\author{
Bildgebende Verfahren in der Orthopädie \\ Narkose beim Pferd \\ Aufgaben des Turniertierarztes \\ Haftpflichtfälle in der Pferdepraxis
}

Anmeldung: BPT, Lyoner Straße 26, 60528 Frankfurt
Tel.: (0 69) 66981 80, Fax: (0 69) 6668170 